\title{
Endocrine manifestations in DiGeorge and other microdeletion syndromes related to $22 q 11.2$
}

\author{
Sofia Kitsiou-Tzeli, Aggeliki Kolialexi, Ariadni Mavrou
}

Department of Medical Genetics, Athens University, St. Sophia's Children's Hospital, 11527 Athens, Greece

\section{INTRODUCTION}

Microdeletions, translocations or other rearrangements of chromosomal region $22 \mathrm{q} 11.2$ have been reported in association with $>80$ different birth defects and malformations occurring in many combinations and with widely differing severity. ${ }^{1}$ Furthermore, a tendency to report atypical cases and ascertainment of published series according to the author's speciality have resulted in the same deletion being linked to a heterogeneous group of disorders that share a common genetic basis, including the DiGeorge (DGS), velocardiofacial (or Shprintzen) (VCFS), and conotruncal anomaly face (CTAF) syndromes. Ninety percent of patients with DGS, $68 \%$ of VCFS, and $30 \%$ of CTAF patients are known to carry this deletion..$^{2-4}$ The prevalence of DGS/VCFS is approximately $1: 4.000^{5}$ and they represent one of the most frequent genetic diseases, taking into consideration that this figure may be

Key words: DiGeorge Syndrome, Endocrine Manifestations, 10p13.p14 Microdeletion, 22q11.2 Microdeletion

Address all correspondence to:

Sofia Kitsiou-Tzeli, Assoc. Professor of Genetics, Department of Medical Genetics, Athens University, St. Sophia's Children's Hospital, 11527 Athens, Greece,

Tel.: +30 210 7467463-4, +30 210-7795553,

FAX: +30 210-7795553, e-mail: skitsiou@med.uoa.gr

Received 26-09-05, Revised 25-10-05, Accepted 28-10-05 underestimated because of the rate of perinatal deaths observed in many cases with a severe congenital heart defect. The acronym "CATCH 22" (Cardiac anomalies, Abnormal face, Thymic hypoplasia, Cleft palate, and Hypocalcaemia) resulting from $22 \mathrm{q} 11$ deletions has also been proposed to describe the phenotype. Deletions on the short arm of chromosome 10 p13p14 are also associated with a DGS-like phenotype but are much less common than 22q11.2 deletions, occurring with an estimated frequency of 1 in 200,000 live births. ${ }^{6}$

\section{CLINICAL PHENOTYPE}

The cardinal symptoms and clinical features of DGS/VCFS with 22q11.2 deletion are conotruncal heart defect with high morbidity and mortality, cellular immunodeficiency due to thymus and parathyroid hypo-plasia or aplasia, hypocalcemia, velopharyngeal insufficiency, and typical dysmorphic faces which include prominent nose, broad nasal root, narrow palpebral fissures, hypertelorism, retro-micrognathia and low-set ears. ${ }^{7,8}$ In at least $10 \%$ of cases examined, an increased frequency of psychiatric diseases, such as schizophrenia or bipolar disorders, has also been observed after longterm follow-up of patients seen initially as infants or young children. ${ }^{9}$ It is likely that those patients with a clustering of abnormalities, such as microcephaly, developmental delay, cleft palate, velopharyngeal insufficiency, and relatively mild heart defects, come to be diagnosed as VCFS, whereas those with more caudal anomalies (thymic and parathyroid hypoplasia, se- 
vere heart defects with right-sided aortic arches) are diagnosed as DGS. ${ }^{10}$

Cardiac malformations, speech delay, and immunodeficiency are the most common characteristics, although no single prominent of feature is overwhelmingly associated with the deletion 22q11.2.,11 None of the phenotypic features is pathognomonic for the deletion, the presence of which does not predict end-organ effects or severity with any certainty. ${ }^{12}$ Nevertheless, a high index of suspicion is warranted for children presenting with the classic manifestations of DGS/VCFS, as well as for patients with a single common manifestation and one or more uncommon ones..$^{13}$ Most affected patients fall near the center of the distribution of severity so that the largest number of cases, which resemble each other, tend to fall near the mode of that distribution. ${ }^{7}$

Patients reported so far with the deletion at 10p13p14 exhibit at least one of the classic features of DGS (cardiac defect, hypocalcemia, and/or immune defect) and they share the following features with DCS/VCFS: cardiac defects, transient hypoparathyroidism/hypocalcemia, T-cell deficiencies, facial anomalies such as low-set and small ears, micrognathia and facial clefts, hypertelorism, short nose with anteverted nares, abnormally shaped skull, microcephaly, hand and foot abnormalities, genitourinary anomalies, hearing loss, and severe psychomotor retardation. ${ }^{14-21}$ An update on the phenotypic manifestation of DGS/VCFS is given on two web sites, serving as excellent resources for families and caregivers (www.vcfsef.org, http://www.cbil. upenn.edu/VCFS/22qandyou/).

\section{MOLECULAR GENETICS OF DIGEORGE SYNDROME CAUSED BY A 22q11.2 DELETION}

DGS/VCFS phenotypes represent the expression of developmental disturbances of neural crest during the embryogenesis of the third and fourth paryngeal pouches and are attributed to the haploinsuffiency of one or more of the genes located in the chromosomal region 22q11.2.22,23

Most patients have an interstitial deletion of $\sim 3$ $\mathrm{Mb}$, the typically deleted region (TDR) ${ }^{24}$ In this region the estimated number of genes is over 100 and since no one gene has been definitely demonstrat- ed to play any specific role, the DCS/CVFS are considered to be contiguous genes syndromes. ${ }^{16,25-27}$

Candidate genes likely to be responsible for the DGS phenotype are: the ubiquitinfusion-degradation-l-like (UFDIL) gene, ${ }^{25-29}$ the TBX1 gene,${ }^{25-31}$ and the platelet glycoprotein gene, $G P 1 b,{ }^{13}$ while other genes may also play a role in the behavioral aspects of the syndrome..$^{32,33}$ The study by Taddei et $\mathrm{al}^{34}$ in a mouse model supported the idea that background genes can influence the phenotypic expression, while it also provided a potential explanation for the diversity seen within single families.

The $22 \mathrm{q} 11.2$ deletion is inherited in $5-10 \%$ of cases, but the observation of phenotypic differences among members of the same family carrying an identical deletion is indicative of a more complicated molecular genetic basis. It has also been shown that the clinical severity is not related to the length of the deletion. ${ }^{32,35}$ Moreover, during the last 5 years a number of reports describing DGS or VCFS-like features in patients with atypical deletions have appeared in the literature, making it difficult to reach an overall conclusion concerning the position of critical genes. ${ }^{36-39}$

The possible mechanisms of 22q11.2 deletion are reviewed in the excellent paper by Scambler ${ }^{1}$. In parents of children with the above deletion, recombination studies detected an excess of meiotic events within 22q11, suggesting that unequal crossing over may occur in the deleted region. ${ }^{40-44}$

Since FISH was implemented as a laboratory test for DGS and VCFS by the disclosure of two signals on chromosomes 22 in normal patients and one signal only when a deletion is present, the number of patients diagnosed has increased dramatically, including patients with mild to severe phenotypes. ${ }^{45}$ In a series of 193 Greek patients referred for DGS/ VCFS to the Department of Medical Genetics of Athens University, a deletion was detected by FISH in $17(12.2 \%)$, confirming the clinical diagnosis. ${ }^{46}$

There are also reports in the literature of patients with DGS/CFS phenotypes but without a 22q11.2 deletion $^{1}$. It is possible that the deletion-negative patients have smaller chromosomal deletions that could not be detected by FISH or have a point mu- 
tation in a critical gene within the TDR critical region of DGS/VCFS. ${ }^{47}$

\section{MOLECULAR GENETICS OF DIGEORGE SYNDROME CAUSED BY A 10p13p14 DELETION}

As already mentioned, deletions on the short arm of chromosome $10 \mathrm{p} 13 \mathrm{p} 14$ are also associated with a DGS-like phenotype but are much less common. ${ }^{6}$ This deletion was first reported by Elliot et al in $1970^{48}$ and a decade later it was associated with DGS anomalies. $^{49-51}$

It has been suggested that there are two nonoverlapping haploinsufficiency regions on 10p which contribute to the DCS/VCFS phenotype. Lichtner et $\mathrm{al}^{18}$ revealed hemizygosity of the proximal region, designated DGCR2, which can cause cardiac defect and $\mathrm{T}$ cell deficiency, while hemizygosity of the distal region, designated HDR1, can cause hypoparathyroidism and, in addition, sensorineural deafness and renal dysplasia/insufficiency or a subset of this triad.

To exclude abnormalities within the 10p13p14 region, a FISH assay was designed. ${ }^{6}$ Also, a dualprobe FISH assay, including test probes for both the DGS I and DGS II loci and centrometric probes specific for chromosomes 22 and 10 has been developed by Berend et $\mathrm{al}^{6}$ and is especially helpful when the clinician requests a FISH test without a standard karyotype.

\section{ENDOCRINE MANIFESTATIONS}

The most frequent endocrine disorders associated with DGS/VCFS are short stature, hypocalcemia, thymic related immunodeficiency, and, less frequently, autoimmune and thyroid disorders.

\section{GROWTH FAILURE}

Short stature is a common problem associated with 22q11.2 microdeletion syndrome $\mathrm{e}^{52}$ and was originally reported in $30 \%$ of VCFS cases ${ }^{53}$ In a review of 120 patients by Goldberg et al, ${ }^{20}$ analysis of growing children with VCFS showed their height to be below the 5th centile. However, among them only about $10 \%$ remained below the predicted height and had true short stature. In the majority of cases the predicted height matched their target height, indicating that a component of the short stature may be caused by constitutional growth delay.

From European collaborative study by Ryan et $\mathrm{al}^{7}$ growth data (sex, height, weight, head circumference) were available in 158 patients with $22 \mathrm{q} 11.2$ deletions. Growth retardation was common; 131/158 $(83 \%)$ of patients had heights/weights below the $50^{\text {th }}$ centile, and 57/158 (36\%) were below the $3^{\text {rd }}$ centile for either height or weight. In the same population, $46 / 120(38 \%)$ of patients with congenital heart disease (CHD) were below the $3^{\text {rd }}$ centile for either height or weight, as compared to $11 / 38$ (29\%) of patients without CHD (not statistically significant). Head circumference measurements were in agreement with those for height and weight. The observation that most babies were born within the normal size range, but $33 / 205(16 \%)$ were below the $3^{\text {rd }}$ and $147 / 205(72 \%)$ were below the $50^{\text {th }}$ centile, suggests an intrinsic problem causing growth retardation. In the same study, childhood measurements were frequently on a lower centile than birth weight, with 57/158 (36\%) being < 3rd and 131/158 (83\%) $<50^{\text {th }}$ centile. According to the authors, this may be related to feeding problems in the neonatal period, while recurrent infections were not considered to play a significant role. Congenital heart defect is one, but not the sole, explanation.

Growth hormone deficiency in patients with $22 \mathrm{q} 11.2$ deletion was reported by Weinzimer et $\mathrm{al}^{52}$ in 4 cases. Growth hormone deficiency with abnormal pituitary anatomy has also been reported in some cases, with growth hormone therapy improving the patient's final height.

In a summary of clinical findings of 250 patients undergoing an extensive multispecialty evaluation at the Children's Hospital of Philadelphia, ${ }^{11}$ short stature was reported in 10-40\% of patients, with growth hormone deficiency in some children who were significantly below the $5^{\text {th }}$ percentile for height. In half of the patients with growth hormone deficiency, pituitary gland abnormalities were diagnosed by MRI. These patients had responded dramatically to growth hormone therapy with accelerated linear growth. It was also observed that short stature 
was present independent of cardiac defects. The authors suggested that growth hormone deficiency, specifically low levels of insulin-like growth factor I and insulin-like growth factor binding protein, should be suspected in children with DGS/VCFS whose height or growth velocity is less than the $5^{\text {th }}$ percentile.

More recently in the study of Brauner et al, ${ }^{54}$ children with 22q11.2 deletion were at birth below - 2SD for weight in $22 \%$ of the cases and for length in $17 \%$. Short stature later on was attributed to intrauterine growth retardation, feeding difficulties, or growth hormone deficiency, as suggested by low insulin-likegrowth factor (IGF-I).

Finally, Choi et $\mathrm{al}^{55}$ in a series of 61 patients with 22 q11.2 microdeletion observed ten patients $(16.4 \%)$ below the $3^{\text {rd }}$ percentile in height, but the serum IGF-1 level was normal in nine and the serum IGFBP-3 levels were normal in all patients. No significant correlation was found between the severity of short stature and the serum IGF-1 and IGFBP-3 levels. In the same study, in 16/61 patients the weight at birth with a full-term gestation was below the $3^{\text {rd }}$ percentile $(26.2 \%)$, indicating intrauterine growth retardation. However, birth length data were not available in most patients; 7/16 patients showed progressive catch-up growth with time.

\section{HYPOCALCEMIA - PARATHYROID DYSFUNCTION}

It has been reported that hypocalcemia results from abnormal third and fourth pharyngeal pouch development, resulting in defective organogenesis or absence of the parathyroid glands..$^{56-58}$

Parathyroid anomalies have been described as one of the typical findings in DGS, and hypocalcemia due to hypoparathyroidism is found in $70 \%$ of patients with the DGS/VCFS phenotype and in 40$60 \%$ of those with the $22 \mathrm{q} 11.2$ deletion. ${ }^{28}$ It is noted that parathyroid function varies among patients and even in the same patient at different times. In most patients presented for clinical evaluation between birth and age 3 months with a variety of symptoms including seizures, tremors, and rigidity, serum measurements of total calcium ranged from 5.5 and 7.1 $\mathrm{mg} / \mathrm{dl} .{ }^{20}$ Severe hypoparathyroidism in the neonate almost always resolves spontaneously and completely, with eventual resolution and without subsequent symptoms or complications, because as the parathyroid glands hypertrophy, hypocalcemia generally improves over the first year of life. ${ }^{13,21,59}$ Hypoparathyroidism with hypocalcemia may or may not recur later in life. ${ }^{21,59}$

Creig et $\mathrm{al}^{21}$ reported transient congenital hypoparathyroidism (TCHP), with spontaneous resolution in infancy and subsequent recurrence in childhood in three patients with (VCFS). The neonatal hypocalcemia in these patients and in another five reported previously, with resolution and later recurrence, were characterized by severe hypocalcemia at onset. In this group as a whole, the majority had seizures $(5 / 8)$, required intravenous treatment with calcium (5/8), and needed prolonged therapy. The authors suggested that in order to distinguish hypocalcemic infants with TCHP from the majority of infants with benign neonatal hypocalcemia, the demonstration of low levels of PTH or of elevated phosphate levels is helpful. Furthermore, neonates with severe hypocalcemia and apparent hypoparathyroidism should receive further evaluation for adequacy of parathyroid secretion and should undergo examination for specific features of VCFS, since these features may not be easily apparent. Infants with resolved TCHP need continuous follow-up of parathyroid function, genetic analysis, and examination for anomalies associated with chromosome $22 \mathrm{q} 11$ deletion. ${ }^{21}$

Prolonged mild hypocalcemia may be unrecognized for a long time, but even mild hypocalcemia may be clinically significant, and the risk is high for arrhythmia, syncope, or sudden death, especially in the adolescent or adult who may have repaired conotruncal cardiac defect. ${ }^{28}$ Even mild hypocalcemia evokes a rapid and sustained increase in intact parathyroid hormone (iPTH) levels in infants, children, and adults. Results from a previous study by Cuneo et $\mathrm{al}^{47}$ demonstrated that in children with Conotructal Cardiac Defects (CTCD) who were normocalcemic at rest, $50 \%$ had a reduced ability to secrete iPTH in response to evoked hypocalcemia, compared with a control population of children with atrial septal defect (ASD). The authors called this response latent hypoparathyroidism, implying 
a reduced iPTH secretory reserve.

Latent hypoparathyroidism, defined as normocalcemia with decreased parathyroid hormone reserve in response to hypocalcemic stress, is not a well known manifestation of the 22q11.2 deletion syndrome. ${ }^{28}$ Latent hypoparathyroidism can progress to overt hypocalcemic hypoparathyroidism, especially during stressful conditions. ${ }^{47}$ The identification of one patient with hypocalcemia at the age of 15 years emphasizes the need for continuous follow-up of patients with VCFS throughout life, especially during times of stress. ${ }^{20}$

The parathyroid function and calcium status were recorded by Ryan et $\mathrm{al}^{7}$ in a cohort of 340 patients; $203 / 340(60 \%)$ had been hypocalcemic and this was generally associated with symptoms in the neonatal period. However, several patients presented with hypocalcemia in childhood and one patient presented at the age of 18 years. Of the 108/203 hypocalcemic patients whose seizures history was documented, 42/108 (39\%) had seizures secondary to hypocalcemia and the majority of them responded well to calcium supplements, with cessation of seizures. The hypocalcemia resolved in 45/64 (70\%) patients and the remainder continued on calcium supplements, but it was not known if parathyroid function had been reassessed. The authors suggest that the calcium-parathyroid hormone axis (ionized calcium plus intact parathyroid hormone levels) should be evaluated regularly in patients with 22q11.2 deletion, while the maintenance therapy for hypocalcemia should include 1,25-dihydroxy vitamin $\mathrm{D}$ with or without oral calcium to maintain serum ionized calcium in the low-normal range.

In a review of chromosome 22q11.2 deletion syndrome (DGS/VCFS) by Perez and Sullivan, ${ }^{13}$ it was emphasized that neonatal hypocalcemia is one of the strongest predictors of a chromosome $22 \mathrm{q} 11.2$ deletion and is present in $17-60 \%$ of patients, depending on the definition used. Few older patients require ongoing calcium supplementation, but it has become increasingly clear that hypocalcemia can develop in older age, presenting with new onset of tetany or seizures in adults with previously undiagnosed disease. ${ }^{60,61}$ It is also known that hypocalcemia can be unmasked in adults under stress, because of acute medical conditions or trauma. This suggests that primary hypocalcemia at any age should be considered a risk for patients with this deletion. ${ }^{13}$

According to a recent report by Brauner et al in $2003,{ }^{54}$ hypocalcemia occurred in $74 \%$ of cases with 22q11.2 deletion when blood calcium concentrations were measured twice during the first 15 days of life, and in $49-60 \%$ of patients during childhood, verifying that hypocalcemia is more frequent in the neonatal period. In the same study a 22q11.2 deletion was found in 10 of 14 patients with hypoparathyroidism.

\section{THYMIC RELATED IMMUNODEFICIENCY AND AUTOIMMUNE ENDOCRINE DISORDERS}

The original description of the syndrome by $\mathrm{Di}-$ George in $1968^{62}$ included a child with hypoparathyroidism and recurrent infections as well as the necropsy findings of three cases with absent thymus and parathyroid glands. A year ago DiGeorge et al reported four athymic infants and in one instance correctly diagnosed the thymic aplasia postmortem. ${ }^{63}$ Although absence of thymus is considered a major feature of the syndrome, in a large collaborative European study in 1997 only 3 out of 263 DGS/ VCFS patients with complete data on immune function had severe immunodeficiency. ${ }^{7}$ Even in cases in which the thymus was absent or the laboratory results were abnormal, clinically significant immunological problems were uncommon. On the other hand, immunodeficiency was reported in $40-93 \%$ of people with the 22q11.2 deletion. ${ }^{11,64,65}$

People with DGS/VCFS phenotype and cardiac detects have been observed with absent or hypoplastic thymus at the time of surgery. Estimates of thymic tissue have been made by transthoracic echocardiography in children with conontruncal cardiac defects. A hypoplactic thymus may increase the likelihood that a deletion may be present. Children, however, with longstanding cardiac disease or heart failure often have a small thymus which predicts present or future immune disorder. ${ }^{28}$ The observation of absent or hypoplastic thymus at the time of cardiac surgery is not infrequent in children with DGS/VCFS phenotype and cardiac defects. 
Cell mediated immune deficiency is expected, especially in patients with the DGS phenotype, but disorders of humoral immunity also occur. ${ }^{28}$ As to the severity of immunodeficiency, most children have a mild form characterized by low absolute $\mathrm{T}$ cell numbers and a small, histologically normal thymus, but normal or near normal T-cell function. At the other end of the spectrum, immunodeficiency may be severe in some patients, characterized by thymic aplasia and absent T-cells. Severely affected people require aggressive immunodeficiency treatment, and they may even need thymic transplantation. The usual clinical picture in younger patients is susceptibility to upper respiratory infections, while older children have fewer infections and increased T-cell numbers and function. Patients suffer from prolonged viral infections and have frequent bacterial superinfections of the upper and lower respiratory tract. The infections are also seen in DGS/VCFS with normal T-cell numbers, suggesting that anatomy, reflux, allergies, cardiac disease, and poor nutrition contribute to the recurrent infections. Of the patients who have a mild to moderate decrease in $\mathrm{T}$-cell production, the absolute $\mathrm{T}$-cell numbers are not predictive of infections. Interestingly, among the few known adults, approximately $25 \%$ have recurrent infections.

The condition is often intensified by the co-existence of velopharyngeal insufficiency and other

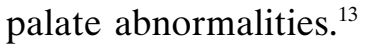

In our series of 17 patients with a confirmed deletion of 22q11.2, lymphocyte subpolulation disturbances were detected in 6 children (47\%) with a mild clinical picture, and only one required prolonged medical treatment with intravenous gamma globulin administration. ${ }^{46}$ It is interesting that one of our patients with a $22 \mathrm{q} 11.2$ deletion, but without neonatal immunological problems, developed lympho$\mathrm{ma}$ at the age of 15 years. To the best of our knowledge, this is the first case of DGS with hematologic malignancy. ${ }^{46}$

The immune status of people with the $22 \mathrm{q} 11.2$ deletion should be ascertained when the diagnosis is made by measurements of $\mathrm{T}$ and $\mathrm{B}$-cell subsets from peripheral blood lymphocytes and by in vitro lymphoproliferative assay of T- cell function. Man- agement of the immunodeficiency in DGS/VCFS is problematic. The use of a fully matched sibling bone marrow transplant or a thymic transplant is required for the profoundly immunodeficient patient. ${ }^{13}$ The broad spectrum of immunodeficiency in chromosome 22q11.2 deletion syndrome makes it difficult to counsel patients and families regarding the morbidity or longterm consequences. ${ }^{12}$

The literature is consistent with the theory that the 22q11.2 microdeletion syndrome is associated with a predisposition to autoimmune disorders, which contributes to the extremely variable phenotypes of affected patients. ${ }^{66}$

Antibody production is generally normal, although IgA deficiency is increased in patients with the deletion and this may predispose patients to autoimmune disorders. ${ }^{12,13}$ Autoimmune disease is seen in approximately $9 \%$ of all patients with the deletion. No one specific autoimmune disease is seen in this syndrome, but the risk of all autoimmune disease seems to be increased.

Autoimmune hemolytic anemia, idiopathic thrombocytopenic purpura, thyroiditis, type 1 diabetes mellitus, and juvenile rheumatoid arthritis have been associated with 22q11.2 microdeletion syndrome. Davies et al in $2001^{67}$ postulated that hemideletion of TBX1 gene could result in premature thymic apoptosis and subsequent qualitative defect in immunological tolerance, thus predisposing to autoimmunity. T-cell defects due to absent or hypoplastic thymus gland can also result in defective cellular immunity. The defects of cellular immunity in 22q11.2 microdeletion patients may predispose to the development of immune dysregulation and autoimmune disorders. However, most of these patients have apparently clinically non-significant T-cell defects and clinical immunodeficiency, or both. Juvenile rheumatoid arthritis is statistically the most common autoimmune disease in children with the deletion. It appears to be more frequent in the subset of patients who have IgA deficiency.

\section{DIABETES MELLITUS}

Diabetes has been described, as has autoimmune thyroid disease, in a substantial subset of patients. 
Elder et al ${ }^{68}$ described a 9-year old boy with clinical findings consistent with velocardiofacial syndrome and a chromosome 22q11.2 deletion. He had the distinctive facial features, learning disabilities, short stature, and he presented with a history of glottic web, clubfoot, polyuria, polydipsia, weight loss, hyperglycemia, ketosis, serum insulin antibodies, and a low C-peptide level. The authors suggested that the presence of insulin antibodies in this patient indicate an autoimmune etiology for his diabetes mellitus type I, and suspected that the defects in immune regulation due to T-cell deficiency in chromosome 22 q11.2 deletion syndrome may predispose to autoimmune disorders, including type I diabetes mellitus.

In the literature there are reports of six children born to diabetic mothers who, among many congenital anomalies, had cardiac defects, absent thymus, and parathyroid glands, as well as renal agenesis. ${ }^{69-73}$ One of them was described as having apparent features of VCFS but without deletion in chromosome 22q11.2. ${ }^{71}$ Elder et al (2001) speculate that it is possible that these diabetic mothers may have undetected microdeletions or some other mutation in the $22 \mathrm{q} 11.2$ region, which could have predisposed them, as well as their children, to 22q11.2 deletion syndrome and potentially diabetes development.

\section{THYROID DYSFUNCTION}

Thyroid hypoplasia was first reported in DGS by Robinson et al in $1975^{74}$ but was not regarded as a component of VCFS until 1993, when Goldberg et $\mathrm{al}^{20}$ observed one patient with hypothyroidism in a series of 120 patients with VCFS. This finding provided additional evidence of VCFS and DGS overlap. Subsequently, hypothyroidism (HP) was reported in more patients with the DGS/VCFS phenotype and 22q11.2 deletions. ${ }^{11,71,73,75}$ In the study of Adachi et al out of 14 children diagnosed as HP, 10 (aged 9 days to 13 years) showed del 22q11.2.

With regards to autoimmune thyroid disease, in 2005 two patients were described, out of a series of 61 with 22q11.2 microdeletion, were described one with Graves' disease and one with Hashimoto thyroiditis, an incidence $(3.3 \%$ ) higher than that of the general population and with an earlier age of on- set. ${ }^{55}$ The 9-year old female with Graves' disease was detected because of abnormal thyroid function at the age of 40 months (TSH $<0.05 \mu \mathrm{U} / \mathrm{ml}$, free $\mathrm{T}_{4}$ $8,1 \mathrm{ng} / \mathrm{dl}$, TSH receptor antibody $96,5 \%$ ) and was treated with methimazol. The other patient, a 12year old female with Hashimoto thyroiditis, who presented with goiter at the age of 10, was diagnosed due to elevated TSH $(13.7 \mu \mathrm{u} / \mathrm{ml})$ and thyroid autoantibody levels, and since then has been treated with sodium L-thyroxine. The authors speculate that in these patients concurrence of autoimmune thyroid disorders with DGS/VCFS was not a chance association.

There are two previous reports of Graves' disease in patients with 22q11.2 deletion. Kawamura et $\mathrm{a}^{76}$ reported an 18-year old female with partial phenotype of DGS, and Kawame et $\mathrm{al}^{66}$ reported four females and one male diagnosed between the ages of 27 months and 16 years, when elevated serum levels of the thyroid hormones were detected, in association with suppressed thyroid-stimulating hormone levels. TSH-receptor antibodies and other characteristic anti-thyroid antibodies, such as antithyroglobulin and anti-microsomal antibodies, were positive in $3 / 5$ patients. The clinical presentations were typical of hyperthyroidism, but in addition one female infant had seizures.

The pathogenetic mechanism of Graves' disease is thought to involve a complex interaction between genetic predisposing factors and environmental triggering ones. None of the several candidate genes, including the TSH receptor gene for nonautoimmune hypertyroidism that have been associated with Graves' disease, is located in the 22q11.2 chromosomal region of DGS/VCFS. Kawame et $\mathrm{al}^{66}$ hypothesized that the combination of T-cell dysfunction, genetic susceptibility, and appropriate environmental triggering factors can precipitate autoimmune disease in some patients with the 22q11.2 deletion syndrome. They also proposed that the association between the 22q11.2 deletion and the development of Graves' disease is not coincidental, taking into consideration the higher incidence of Graves' disease among patients with the 22q11.2 deletion syndrome evaluated at the Children's Hospital, Philadelphia (1 in 352) than in the general population (17.7 in 100,000): This figure is approximately 16 
times higher than the one seen in the general population.

Although the prevalence and the natural history of thyroid dysfunction in DGS/VCFS are not well characterized, baseline thyroid-stimulating hormone and T4 levels are highly recommended, since hypothyroidism is a treatable cause of both short stature and learning disabilities. ${ }^{28}$ Clinicians should also be aware of the possibility of Graves' disease in patients with a 22q11.2 deletion at any age and evaluation of thyroid hormone function is indicated in patients with the syndrome and suggestive features of hyperthyroidism. ${ }^{66}$

\section{CONCLUSION}

Despite our increased understanding of the clinical spectrum and molecular genetics of the 22q11.2 syndromes, questions about the contributing factors in the extremely variable phenotypes still remain. Phenotypically similar people have deletions on different chromosomes, or are cytogenetically normal. In the field of clinical endocrinology, there is concern about the natural history of endocrine abnormalities in this syndrome and increased awareness of this syndrome, facilitate the early recognition of the abnormality.

Regarding the clinical management of patients with 22q11.2 deletion, they should be monitored for their height, weight, and parathyroid function. $\mathrm{GH}$ secretion and plasma IGF-1 should be evaluated in those who do not show any catch-up growth after intrauterine growth restriction or who have an unexplained slow growth rate. Those with a low GH peak and/or IGF-I may need magnetic resonance imaging to detect pituitary abnormalities. Pituitary hypoplasia may suggest GH deficiency. Nutritional conditions should be optimized and, whenever possible, pharyngeal abnormalities should be carefully corrected. In addition, the blood concentrations of ionized and total calcium and of PTH should be regularly measured, particularly in the neonatal and pubertal periods and at surgery, while parents and patients should be informed about the signs of hypocalcemia: paresthesias, cramps, and or rigidity. ${ }^{54}$

In conclusion, an optimal wide-ranging program for medical care, including not only cardiac and immunologic follow-up, cognitive, speech, language, and neuropsychiatric evaluation, but also endocrine perspectives, are needed in order to limit the disabilities of patients with DGS/VCFS.

\section{REFERENCES}

1. Scambler PJ, 2000 The 22q11 deletions syndromes. Hum Mol Genet 9: 2421-2426.

2. Greenberg F, 1993 DiGeorge syndrome: a historical review of clinical and cytogenetic features. J Med Genet 30: 803-806.

3. Hall JG, 1993 CATCH 22. J Med Genet 30: 801-802.

4. Lynch DR, McDonald-McGinn DM, Zackai EH, et al, 1995 Gerebellar atrophy in a patient with velocardiofacial syndrome. J Med Genet 32: 561-563.

5. Yamagishi H, 2002 The 22q11.2 deletion syndrome. Keio J Med 51: 77-88.

6. Berend SA, Spikes AS, Kashork CD, Wu JM, Daw SC, Scambler PJ, 2000 Dual-probe Fluorescence In Situ Hybridization assay for detecting deletions associated with DGS/VCFS I and II loci. Am J Med Genet 91: 313-317.

7. Ryan AK, Goodship JA, Wilson DI, et al, 1997 Spectrum of clinical features associated with interstitial chromosome 22q11 deletions: a European collaborative study. J Med Genet 34: 789-804.

8. Vantrappen G, Devriendt K, Swillen A, Rommel N, Vogels A, Eyskeus B, 1999 Presenting symptoms and clinical features in 130 patients with the velo-cardiofacial syndrome. The Leuven experience. Genet Couns 10: 3-9.

9. Shprintzen RJ, Goldberg R, Golding-Kushner KJ, Marion RW, 1992 Late onset psychosis in the velocardio-facial syndrome. Am J Med Genet 42: 141-142.

10. Kelly D, Goldberg R, Wilson D, et al, 1993 Confirmation that the velo-cardio-facial syndrome is associated with haplo-insufficiency of genes at chromosome 22q11. Am J Med Cenet 45: 308-312.

11. McDonlald-McGinn DM, Kirschner R, Goldmuntz E, et al, 1999 The Philadelphia story: the 22q11.2 deletion: report on 250 patients. Genet Couns 10: 11-14.

12. Jawad AF, McDonald-Mcginn DM, Zackai E, Sullivan KE, 2001 Immunologic features of chromosome 22q11.2 deletion syndrome (DiGeorge syndrome/velocardiofacial syndrome). J Pediatr 139: 715-723.

13. Perez E, Sullivan KE, 2002 Chromosome 22q11.2 deletion syndrome (DiGeorge and velocardiofacial syndromes). Curr Opin Pediatr 14: 678-683.

14. Shapira M, Borochowitz A, Bar-El H, Dar H, Etzioni A, Lorber A, 1994 Deletion of the short arm of chromosome 10 (10p13): report of a patient and review. Am J Med Genet 52: 34-38. 
15. Schuffenhauer S, Lichtner P, Peykar-Derakhshandeh $\mathrm{P}$, et al, 1998 Deletion mapping on chromosome 10p and definition of a critical region for the second DiGeorge syndrome locus (DGS2). Eur J Hum Genet 6: 213-25.

16. Gottlieb S, Driscoll DDA, Sellinger B, Emanuel B, Budarf ML, 1998 Characterization of 10p deletion suggests two non-overlapping region contribute to the DiGeorge syndrome phenotype. Am J Hum Genet 62: 495-498.

17. Van Esch H, Groenen P, Daw S, et al, 1999 Partial DiGeorge syndrome in two patients with a $10 \mathrm{p}$ rearrangement. Clin Genet 13: 458-60.

18. Lichtner P, Konig R, Hasegawa T, Van Esch H, Meitinger T, Schuffenhauer S, 2000 An HDR (hypoparathyroidism, deafness, renal dysplasia) syndrome locus maps distal to the DiGeorge syndrome region on 10p13/14. J Med Genet 37: 33-37.

19. Lipson A, Fagan K, Colley A, et al, 1996 Velo-cardiofacial and partial DiGeorge phenotype in a child with interstitial deletion at 10p13 - implications for cytogenetic and molecular biology. Am J Med Genet 65: 304308.

20. Goldberg R, Motzkin B, Marion R, Scambler PJ, Shpritzen JR, 1993 Velo-cardio-facial syndrome: a review of 120 patients. Am J Genet 45: 313-319.

21. Greig F, Paul E, DiMartino-Nardi J, Saenger P, 1996 Transient congenital hypoparhyroidism: resolution and recurrence in chromosome $22 \mathrm{q} 11$. deletion. J Pediatr 128: 563-567.

22. Lammer EJ, Opitz JM, 1986 The DiGeorge anomaly as a developmental field defect. Am J Med Genet 2: Suppl: 113-127.

23. Van Mierop LH, Kutsche LM, 1986 Cardiovascular anomalies in DiGeorge syndrome and importance of neural crest as a possible pathogenetic factor. Am J Cardiol 58: 133-137.

24. Emanuel BS, Budarf BS, Scambler PJ, 1998 The genetic basis of conotructal heart defects: the chromosome 22q11.2 deletion. In: Rosenthal N, Harvey R (eds) Heart Development, Academic Press.

25. Lindsay EA, Halford S, Wadey R, Scambler PJ, Baldini A, 1993 Molecular cytogenetic characterization of the DiGeorge syndrome region using fluorescent in situ hybridization. Genomics 17: 403-407.

26. Levy A, Demezuk S, Aurias A, Depetris D, Mattei MG, Philip N, 1995 Interstitial 22q11 microdeletion excluding the ADU breakpoint in a patient with DiGeorge syndrome. Hum Molec Genet 4: 2417-2419.

27. Rizzu P, Lindsay EA, Taylor C, et al, 1996 Cloning and comparative mapping of a gene from the commonly deleted region of DiGeorge and Velocardiofacial syndromes conserved in C. elegans. Mamm Genome 7: 639-643.

28. Cuneo BF, 2001 22q11.2 deletion syndrome: DiGeorge, velocardiofacial and conotruncal anomaly face syn- dromes. Curr Opin Pediatr 13: 465-472.

29. Yamagishi H, Garg V, Matsuoka R, et al, 1999 A molecular pathway revealing a genetic basis for human cardiac and craniofacial defects. Science 283: 11581161.

30. Merscher S, Funke B, Epstein JA, et al, 2001 TBX1 is for cardiovascular defects in velo-cardio-facial/DiGeorge syndrome. Cell 10: 619-629.

31. Jerome LA, Papaioannou VE, 2001 Di George syndrome phyenotype in mice mutant for the T-box gene, Tbx1. Nat Genet 27: 286-291.

32. Kimber WL, Hsieh P, Hirotsune S, Yna-Paylor L, Sutherland HF, Chen A, 1999 Deletion of $150 \mathrm{~kb}$ in the minimal DiGeorge/Velocardiofacial syndrome clinical region in mouse. Hum Molec Genet 8912: 2229-2237.

33. Paylor R, Mcllwan KL, McAninch R, et al, 2001 Mice deleted for the DiGeorge/velocardiofacial syndrome region show abnormal sensorimotor gating and learning and memory impairments. Hum Mol Genet 10: 2645-2650.

34. Taddei 1 Morishima M, Huynh T, et al, 2001 Genetic factors are major determinants of phenotypic variability in a mouse model of the DiGeorgeldel 22q11 syndomes. Proc Natl Acad Sci USA 98: 11428-11431.

35. Carlson C, Papolos D, Pandita RK, et al, 1997 Molecular analysis of velo-cardio-facial syndrome patients with psychiatric disorders. Am J Hum Genet 60: 851859.

36. Kurahashi H, Nakayama T, Osugi Y, et al, 1996 Deletion mapping of 22q11 in CATCH22 syndrome: indentification of a second critical region. Am J Hum Genet 58: $1377-1881$.

37. O’Donnell H, McKeown C, Gould C, Morrow B, Scambler P, 1997 Detection of a deletion within 11q11 which has no overlap with the Di George syndrome critical region. Am J Hum Genet 60: 1544-1548.

38. McQuade L, Christodoulou J, Budarf B, et al, 1999 Patient with a 22q11.2 deletion with no overlap of the minimal Di George syndrome critical region (MDGCR). Am J Med Genet 86: 27-33.

39. Amati F, Conti E, Novelli A, et al, 1999 Atypical deletions suggests five $22 \mathrm{q} 11.2$ critical regions related to the DiGeorge/velo-cardio-facial syndrome. Eur J Hum Genet 7: 903-909.

40. Halford S, Lindsay E, Nayudu M, 1993 Low-copy-repeat sequences flank the DiGeorge/velo-cardio-facial syndrome loci at 22q11. Hum Mol Genet 2: 191-196.

41. Edelmann L, Pandita R, Spiteri E, et al, 1999 A common molecular basis for rearrangement disorders on chromosome 22q11. Hum Mol Genet 8: 1157-1167.

42. Edelmanm L, Pandita RK, Morrow BE, 1999 Low-copy repeats mediate the common 3-Mb deletion in patients with velo-cardio-facial syndrome. Am J Hum Genet 64: 1076-1086.

43. Shaikh TH, Kurahashi H, Saitta SG, et al, 2000 Chromosome 22-specific low copy repeats and the 22q11.2 
deletion syndrome: genomic organization and deletion endpoint analysis. Hum Mol Genet 9: 489-501.

44. Edelman L, Spiteri E, McCain N, et al, 1999 A common breakpoint on 11q23 in carriers of the constritutional t11:22 translocation. Am J Hum Genet 65: 16081616.

45. Devriendt K, Fryns JP, Mortier G, Van Thienen MN, Keymolen K, 1998 The annual incidence of DiGeorge/ velocardiofacial syndrome. J Med Genet 35: 789-790.

46. Kitsiou-Tzeli S, Kolialexi A, Fryssira H, et al, 2004 Detection of 22q11.2 deletion among 139 patients with DiGeorge/Velocardiofacial syndrome features. In Vivo. 18: 603-608.

47. Cuneo BF, Langman CB, Ilbawi MN, Ramakrishnan V, Cutilletta A, Driscoll DA, 1996 Latent hypoparathyroidism in children with conotruncal cardiac defects. Circulation 93: 1702-1708.

48. Elliot D, Thomas GH, Condron CJ, Khuri N, Richardson F, 1970 C-group chromosome abnormality (?10p-). Occurrence in child with multiple malformations. Am J Dis Childr 119: 72-73.

49. Hervé J, Warnet JF, Jeaneau-Bellego E, Portnoi MF, Taillemitte JL, Hervé F, 1984 Monosomie partielle du bras court d'un chromosome 10, associée à un syndrome de Rieger et à un déficit immunitaire partiel, type DiGeorge, Ann Pédiat 31: 77-80.

50. Fisher E, Scambler P, 1994 Human haploinsufficiency -one for sorrow, two for joy. Nature Genet 7: 5-7.

51. Daw SCM, Taylor C, Kraman M, et al, 1998 A common region of 10p deleted in DiGeorge and velocardiofacial syndromes. Nat Genet 13: 458-460.

52. Weinzimer SA, McDonald-McGinn DM, Driscoll DA, et al, 1998 Growth hormone deficiency in patients with $22 q 11.2$ deletion: expanding the phenotype. Pediatrics 101: 929-932.

53. Shprintzen RJ, Goldberg RB, Young D, Wolford L, 1981 The velo-cardio-facial syndrome: a clinical study and genetic analysis. Pediatrics 67: 167-172.

54. Brauner R, Le Harivel de Gonneville A, Kindermans C, et al, 2003 Parathyroid function and growth in 22q11.2 deletion syndrome. J Pediatr 142: 504-508.

55. Choi JH, Shin YL, Kim GH, et al, 2005 endocrine manifestation of chromosome 22q11.2 microdeletion syndrome. Horm Res 63: 294-299.

56. Taitz LS, Zarate-Salvador C, Schwartz E, 1966 Congenital absence of the parathyroid and thymus glands in an infant (IIIrd and IVth paryngeal pouch syndrome). Pediatrics 38: 412-418.

57. Harvey CJ, Dungan WT, Elders MJ, Hughes ER, 1970 Third and fourth pharyngeal pouch syndrome, associated vascular anomalies and hypocalcemic seizures. Clin Ped 9: 496-499.

58. Conley ME, Beckwith JB, Mancer JFK, Tenckhoff L, 1979 The spectrum of the DiGeorge syndrome. J Pediatr 94: 883-890.

59. Scire G, Dallapicolla B, Lannetti P, 1994 Hypoparathy- roidism as the major manifestation in two patients with 22q11 deletions. Am J Med 52: 478-482.

60. Brandenburg VW, Mertens PR, Block F, et al, 2001 Razidivierende hypokalzamische Tetanien, generalizierte Anfalle und gehaufte bronchopulmonale Infecte bei einem 18-jahrigen Petienten. Internist 42: 10351038.

61. Graedsal A, Suren P, Vadstrup S, 2001 DiGeorge syndrom-underdiagnostisert sykdomsgruppe med mange fremtredelsesfomer. Tidsskrift for Den Norske Laegeforening 121: 3177-3179.

62. DiGeorge AM 1968 Congenital absence of the thymus and its immunologic consequences: concurrence with congenital hypothyroidism. In: Good RA, Bergsma D (eds) Birth Defects, March of Dimes, National Foundation Press, New York; pp, 116-121.

63. DiGeorge AM, Lischer HW, Dacou C, Arey JB, 1967, Absence of the thymus, Lancet 1: 1387.

64. Smith CA, Driscoll DA, Emanuel BS, et al, 1998 Increased prevalence of immunoglobulin A deficiency in patients with the chromosome 22q11.2 deletion syndrome (DiGeorge syndrome/velocardiofacial syndrome). Clin Diagn Lab Immunol 5: 415-417.

65. Duke SG, Mcquirt WF Jr, Jewett T, et al, 2000 Velocardiofacial syndrome: incidence of immune cytopenias. Arch Otolaryngol Head Neck Surg 126: 1141-1145.

66. Kawame H, Adachi M, Tachibana K, et al, 2001 Graves' disease in patients with 22q11.2 deletion. J Pediatr 139: 892-895.

67. Davies K, Stiehm ER, Woo P, Murray KJ, 2001 Juvenile idiopathic polyarticular arthritis and IgA deficiency in the 22q11 deletions syndrome. J Rheumatol 28: 23262334.

68. Elder DA, Kaiser-Rogers K, Aylsworth AS, Calikoglu AS, 2001 Type I diabetes mellitus in a patient with chromosome 22q11.2 deletion syndrome. Am J Med Genet 101: 17-19.

69. Black FO, Spanier SS, Kohut RI, 1975 Aural abnormalities in partial DiGeorge syndrome. Arch Otolaryngol Head Neck Surg 101: 129-134.

70. Gosseye S, Golaire MC, Verellen G, Van Lierde M, Claus D, 1982 Association of bilateral renal agenesis and DiGeorge syndrome in an infant of a diabetic mother. Helv Paediatr Acta 37: 471-474.

71. Wilson DI, Burn J, Scambler P, Goodship J, 1993 Di George syndrome: part of CATCH 22. J Med Genet 30: 852-856.

72. Novak RW, Robinson HB, 1994 Coincident DiGeorge anomaly and renal agenesis and its relation to maternal diabetes. Am J Med Genet 50: 311-312.

73. Digilio MC, Marino B, Formigari R, Diannoti A, 1995 Maternal diabetes causing DiGeorge anomaly and renal agenesis. Am J Med Genet 55: 513-514.

74. Robinson HR Jr, 1975 DiGeorge's or the III-IV pharyngeal pouch syndrome. Pathology and atheory of pathogenesis. Perspect Pediatr Pathol 173-204. 
75. Adachi M, Tachibana K, Masuno M, et al, 1998 Clinical characteristics of children with hypoparathyroidism due to 22q11.2 microdeletion. Eur J Pediatr 157: 34-38.
76. Kawamura T, Nimura I, Hanafusa M, et al, 2000 DiGeorge syndrome with Graves' disease: A case report. Endocr J 47: 91-95. 